\title{
Conventional surgical repair of traumatic rupture of the thoracic aorta
}

\author{
Kiyoshi Chiba $\cdot$ Hiroyuki Abe $\cdot$ Yosuke Kitanaka $\cdot$ \\ Takeshi Miyairi $\cdot$ Haruo Makuuchi
}

Received: 20 October 2013/ Accepted: 2 May 2014/Published online: 6 June 2014

(C) The Author(s) 2014. This article is published with open access at Springerlink.com

\begin{abstract}
Objective Traumatic rupture of the thoracic aorta is a lifethreatening injury requiring urgent surgical intervention. Despite recent improvements in resuscitation and emergency operative techniques, the outcomes of patients with multiple injuries are still associated with a high mortality rate. We retrospectively examined the preoperative demographic data, associated complications and mortality rate of these patients.

Materials and methods $\mathrm{We}$ analyzed the data (1991-2009) of 18 patients with acute traumatic rupture of the thoracic aorta. Most patients had rupture limited to the aortic isthmus and severe associated injuries in other organs. The aorta was repaired by direct suturing, patch plasty $(n=5 ; 27.7 \%)$ or graft interposition $(n=9$; $50 \%)$.

Results The overall mortality rate was $33.3 \%$. All six patients who underwent emergency surgery within $2 \mathrm{~h}$ died, four intra-operatively and two postoperatively. The causes of the intra-operative mortality were uncontrollable hemorrhage and irreversible cardiac arrest due to penetrating injury of the thoracic aorta and intercostal arteries in three patients, and uncontrollable hemorrhage due to severe liver laceration in one. The surgical complications $(42.8 \%)$ were acute lung injury $(n=2)$, liver insufficiency
\end{abstract}

K. Chiba $(\bowtie) \cdot$ Y. Kitanaka · T. Miyairi · H. Makuuchi Department of Cardiovascular Surgery, St. Marianna University School of Medicine, 2-16-1 Sugao Miyamaeku, Kawasaki, Kanagawa 216-8511, Japan

e-mail: kiyo-82@marianna-u.ac.jp

H. Abe

Department of Cardiovascular Surgery, St. Marianna University School of Medicine, Yokohama Seibu Hospital, Yokohama, Kanagawa, Japan $(n=2)$, acute renal failure $(n=1)$ and cerebral infarction $(n=1)$. No patients had postsurgical paraplegia. The mean period between arrival and treatment and the mean Injury Severity Score were significantly higher in group D than in group A.

Conclusion To improve the outcome of traumatic thoracic aortic injury, the degree of multi-organ damage, the priority of treatment be evaluated accurately is important.

Keywords Traumatic aortic rupture $\cdot$ Revised Trauma Score (RTS) · Injury Severity Score (ISS) · Surgical repair

\section{Introduction}

Traumatic rupture of the thoracic aorta is severe injury with high mortality.

In the recent reports, more than $80 \%$ of the patients with severe injuries die from lethal exsanguinations at the scene of the accident; only 15-20\% are transported to the hospital alive [1,2]. Statistical data on trauma in Japan are few, but more than 40,000 people are reported to die every year due to trauma in Japan [3].

According to the Japan trauma databank, the most frequent cause of death is a blunt trauma by traffic accident $(39.2 \%)$ or fall $(19.9 \%)$. The sites of trauma are the head in $21.1 \%$, the chest in $15.3 \%$ and the lower extremities in $21.1 \%$. Hence, traumatic rupture of the thoracic aorta in Japan is caused mainly by blunt trauma.

Prompt surgical repair for thoracic aortic injury is generally recommended. If the patient has more immediate life-threatening injuries that require emergency laparotomy or craniotomy, however, the aortic repair may be delayed according to the guidelines 2000 Eastern Association for Surgery of Trauma (EAST) [4]. 
Table 1 Pre- and postoperative clinical data of patients

\begin{tabular}{|c|c|c|c|c|c|c|c|}
\hline No & Sex & Age & RTS & ISS & Body area of AIS $>3$ & Procedure & Outcome \\
\hline 1 & $\mathrm{~F}$ & 56 & 5.24 & 50 & Head (3), chest (5), extremity (4) & Direct closure $\rightarrow$ TAE & Alive \\
\hline 2 & M & 25 & 5.24 & 35 & Chest (5), extremity (3) & Grafting & Alive \\
\hline 3 & M & 47 & 5.97 & 50 & Chest (5), abdominal (3), extremity (4) & TAE $\rightarrow$ direct closure & Alive \\
\hline 4 & M & 63 & 7.11 & 35 & Chest (5), extremity (3) & Direct closure & Alive \\
\hline 5 & M & 25 & 4.94 & 50 & Head (3), chest (5) extremity (4) & TAE $\rightarrow$ direct closure & Alive \\
\hline 6 & M & 22 & 3.57 & 43 & Head (3), chest (5) abdominal (3) & Grafting + small bowl resection & Alive \\
\hline 7 & M & 39 & 7.84 & 26 & Chest (5) & Grafting & Alive \\
\hline 8 & M & 45 & 3.07 & 50 & Head (3), chest (5) extremity (4) & TAE $\rightarrow$ Grafting pelvic external fixation & Alive \\
\hline 9 & M & 18 & 7.84 & 43 & Chest (5), abdominal (3), extremity (3) & Grafting & Alive \\
\hline 10 & M & 38 & 7.11 & 43 & Head (3), chest (5), extremity (3) & Grafting + femoral fixation & Alive \\
\hline 11 & M & 18 & 7.84 & 35 & Chest (5), extremity (3) & Grafting + femoral fixation & Alive \\
\hline 12 & M & 19 & 7.84 & 30 & Chest (5) & Grafting & Alive \\
\hline 13 & $\mathrm{~F}$ & 69 & 4.5 & 65 & Chest (5), abdominal (6) & Partial hepatectomy ET (direct closure) & Dead \\
\hline 14 & M & 17 & 7.55 & 45 & Chest $(5 \rightarrow 6)$, extremity (3) & ET & Dead \\
\hline 15 & M & 20 & 4.5 & 75 & Chest (5), abdominal (5), extremity (5) & TAE $\rightarrow$ grafting & Dead \\
\hline 16 & M & 81 & 5.5 & 70 & Head (3), chest (5), abdominal (6) & $\mathrm{EL}+\mathrm{ET}$ & Dead \\
\hline 17 & M & 17 & 5.3 & 45 & Head (3), chest $(5 \rightarrow 6)$ & ET & Dead \\
\hline 18 & M & 18 & 6.9 & 45 & Head (3), chest (6) & ET & Dead \\
\hline
\end{tabular}

Injury Severity Score is allocated to each of the six body regions [head, face, chest, abdomen, extremities (including the pelvis) and external]. Only the highest Abbreviated Injury Score (AIS) in each body region is used as a final score (aortic injury is excluded in the calculation of chest AIS). The scores of the three most severely injured body regions are squared and summed to produce the final ISS

TAE transcathetral arterial embolization, EL emergency laparotomy, ET emergency thoracotomy, RTS Revised Trauma Score, ISS Injured Severity Score

In patients with multiple injuries, it is reported that better results are obtained by treating severe and more urgent extra-aortic trauma to stabilize the general condition before performing the aortic repair [4].

On the other hand, despite developments in trauma management and operative techniques, still remains high mortality.

The purpose of this retrospective study was to consider the associations of the preoperative demographic data, such as Injury Severity Score (ISS) [5], and physiologic scoring system (Revised Trauma Score, RTS) [6] in acute settings, to determine surgical strategies to reduce the incidence of mortality. ISS, which proposed by Baker et al. in 1974, has become world-wide standard for to determine the severity of injury. Calculation of the ISS is severity scores based on contains the Abbreviated Injury Scale (AIS) [5].

\section{Patients and methods}

We analyzed the data of 18 patients with acute traumatic rupture of the thoracic aorta who had undergone treatment at our institution between September 1991 and November 2009. Data were obtained by retrospectively reviewing medical records and operative reports. The age range was from 17 to 81 years (mean, $43.8 \pm$ years). All patients had blunt chest trauma involving sudden deceleration (traffic accidents, $72.2 \%$ ) or a fall from a great height $(27.8 \%)$.

A diagnosis of traumatic rupture of the thoracic aorta was established by chest X-ray imaging, together with computed tomography (CT) or angiography [7-9]. The diagnosis by CT required clear signs of aortic injury such as pseudoaneurysm, intimal flap, aortic contour abnormality, intraluminal thrombus or pseudocoarctation.

Most of the patients had a typical rupture of the aortic isthmus $(76.5 \%)$, and 5 had a rupture of the descending aorta $(23.5 \%)$. Table 1 shows the demographic and clinical data of the patients. All patients had associated injuries in various organs; there were additional severe lesions, including craniocerebral injury in 6 , lung contusion with reduced respiratory function in 1 and hemopneumothorax in 12 , injury to multiple extremities in 9 , and pelvic fractures in 6 , as visceral organ injuries in the trunk, liver laceration in 4 , renal laceration in 3 , spleen laceration in 1 , and injury to superior mesenteric artery and small intestine in 1 (Table 2).

For the anatomic scoring system, we used the ISS, with a range from 0 to 75 . ISS is considered to correlate with mortality from external wounds. The ISS is allocated to 
Table 2 Associated injuries (body area of AIS > 3)

\begin{tabular}{|c|c|c|c|c|}
\hline $\mathrm{N}$ & Head and neck & Face and chest & Abdomen & Extremity (including pelvis) external \\
\hline 1 & Subdural hematoma & Rib fractures & & Femoral fractures \\
\hline 2 & & Hemopneumothorax & & Femoral fractures \\
\hline 3 & & Tension pneumothorax & $\begin{array}{l}\text { Spleen lacerations } \\
\text { Kidney lacerations }\end{array}$ & Pelvic fractures \\
\hline 4 & & Rib fractures & & Femoral fracture \\
\hline 5 & Cerebral contusion & Hemopneumothorax lung contusion & & Pelvic fractur \\
\hline 6 & $\begin{array}{l}\text { Cerebral contusion } \\
\text { Cervical fracture }\end{array}$ & Rib fractures & $\begin{array}{l}\text { Injury to superior mesenteric artery } \\
\text { Injury to small intestine }\end{array}$ & Extremity fracture \\
\hline 7 & Facial laceration & Rib fractures & & \\
\hline 8 & & Rib fractures & & $\begin{array}{l}\text { Pelvic fracture } \\
\text { Extremity fracture }\end{array}$ \\
\hline 9 & & Hemopneumothorax & Kidney laceration & Femoral fracture \\
\hline 10 & Cerebral contusion & Hemopneumothorax & Liver laceration & Femoral fracture \\
\hline 11 & Facial laceration & Hemopneumothorax & & Pelvic fracture \\
\hline 12 & & Hemopneumothorax & & Extremity fracture \\
\hline 13 & & Sever pulmonary insufficiency & Liver ulceration & \\
\hline 14 & & Hemopneumothorax & & Femoral fracture \\
\hline 15 & & $\begin{array}{l}\text { Hemopneumothorax } \\
\text { Rib fractures }\end{array}$ & $\begin{array}{l}\text { Liver lacerations } \\
\text { Kidney ulceration }\end{array}$ & Pelvic fracture \\
\hline 16 & & Hemopneumothorax & Liver laceration & Pelvic fracture \\
\hline 17 & Cerebral contusion & Hemopneumothorax & & \\
\hline 18 & $\begin{array}{l}\text { Vertebral fracture } \\
\text { Spinal injury }\end{array}$ & $\begin{array}{l}\text { Hemopneumothorax } \\
\text { Rib fractures }\end{array}$ & & \\
\hline
\end{tabular}

each of the 6 body regions: head, face, chest, abdomen, extremities (including the pelvis) and external regions. The highest Abbreviated Injury Score (AIS-90) of each body region is used (Table 3 ). The scores of the 3 most severely injured body regions are squared and added together to produce a final ISS (Table 1) [5].

$<\mathrm{ISS}=(\text { highest AIS })^{2}+(2 \text { nd AIS })^{2}+(3 \text { rd AIS })^{2}>$

The physiologic scoring system (RTS) is used to determine the rate of survival according to consciousness, systolic blood pressure and respiratory rate scores (Table 4) [6].

\section{Treatment}

We aimed to perform surgical repair immediately after admission, unless severe associated injuries or complications restricted treatment options. Hypertension was prevented by deep sedation and treated if necessary with the calcium-blocking drug and/or nitroprusside.

In the present study, 18 patients underwent surgical repair for traumatic aortic rupture. Of these patients, 17 $(94.4 \%)$ were treated within 7 days; in nine patients, emergency surgery was performed within $6 \mathrm{~h}$ after the trauma. Four patients underwent surgery without cardiopulmonary bypass Femoro-femoral bypass was established with systemic heparinization in four patients. A minimal amount of heparin was administered to maintain cardiopulmonary bypass keeping activated coagulation time (ACT) at approximately 200-250 s. In ten patients, left heart bypass with the Bio-Pump (Bio-Medicus, Minneapolis, MN, USA) was performed with argatroban, an antithrombin agent. Four patients with critical intra-abdominal injuries or pelvic fractures on arrival had to undergo immediate transcatheter arterial embolization (TAE) of the bleeding arteries before surgical repair. In one of these patients, surgery was delayed for more than 20 days after the initial trauma due to severe pulmonary contusion and severe inflammation after TAE of the bilateral internal iliac arteries. In another patient with pelvic fracture, the bleeding aggravated after surgical repair of traumatic aortic rupture, and therefore, we had to immediately perform TAE of the internal iliac arteries.

In all cases, the thoracic aorta was approached via a lateral or posterolateral thoracotomy, with an incision in the fourth left intercostal space. The aorta was dissected and isolated circumferentially proximal and distal to the injured segment and then clamped proximally between the 
left common carotid artery and the left subclavian artery. In five patients $(27.7 \%)$, the aorta was repaired by direct suturing or patch plasty, and in nine patients $(50 \%)$, a tube-graft was interposed. After weaning from bypass, the effects of heparin were reversed with protamine sulfate. The remaining four patients $(22.3 \%)$ underwent emergency thoracotomy and laparotomy in outpatient room due to the hemorrhagic shock of bleeding and passed away before aortic reconstruction.

Postoperatively, patients were transferred to the intensive care unit with continuous monitoring of arterial and central venous pressure, renal function, consciousness and other hemodynamic and clinical parameters. Follow-up was conducted by office visits and hospital reports.

Table 3 Anatomic scoring system

\begin{tabular}{l} 
Abbreviated Injury Score (AIS)-90 \\
\hline AIS $1=$ minor \\
AIS $2=$ moderate \\
AIS $3=$ serious (nonlife-threatening injury) \\
AIS $4=$ severe (life-threatening but survival) \\
AIS $5=$ critical, survival uncertain \\
AIS $6=$ maximum (currently untreatable)
\end{tabular}

AIS is allocated to each of the six types of injury

Table 4 Physiologic scoring system

\begin{tabular}{llll}
\hline Revised Trauma Score (RTS) & & \\
\hline GCS & SBP & RR & Score \\
\hline $13-15$ & $\geq 90$ & $10-29$ & 4 \\
$9-12$ & $76-89$ & $\geq 30$ & 3 \\
$6-8$ & $50-75$ & $6-9$ & 2 \\
$4-5$ & $1-49$ & $1-5$ & 1 \\
3 & 0 & 0 & 0
\end{tabular}

Revised Trauma Score (RTS) is allocated to each of the five points on the Glasgow coma scale, systolic blood pressure and RR (respiration rate). These three scores are then summed to produce the RTS

$\mathrm{RTS}=0.9368 \times$ GCS Score $+0.7326 \times \mathrm{SBP}$ Score $+0.2908 \times$ RR Score

GCS Glasgow Coma Scale, SBP systolic blood pressure, $R R$ respiratory rate
A $p$ value of $<0.05$ was considered to represent a statistically significant difference on analysis with the Student's $t$ test and Welch test (Table 5).

\section{Results}

We divided all patients into either group A (alive; $n=12$ ) or group D (dead; $n=6$ ) (Table 5). We then estimated possible correlations among age, period between wounding and arrival at hospital, period between arrival at the hospital and operation, and preoperative clinical data. The average patient age was $34.6 \pm 15.7$ years (range 18-63 years) in group A and $37 \pm 29.7$ years (range $17-81$ years $)$ in group $\mathrm{D}(p=0.86)$. The mean period \pm SD between injury and arrival at the hospital was $413.5 \pm 1,179.5 \mathrm{~min}$ (median $32.5 \mathrm{~min}$; range $28 \mathrm{~min}-$ 3 days) in group $A$ and $70.5 \pm 83.6 \mathrm{~min}$ (median $41.5 \mathrm{~min}$; range $9-255 \mathrm{~min})$ in group $\mathrm{D}(p=0.81)$. The mean period between arrival at the hospital and operation was $47.9 \pm 130.4 \mathrm{~h}$ (median $9.1 \mathrm{~h}$; range $1.8 \mathrm{~h}-20$ days) in group $\mathrm{A}$ and $2.6 \pm 1.8 \mathrm{~h}$ (median $1.9 \mathrm{~h}$; range $0.5-5.3 \mathrm{~h})$ in group D $(p<0.02)$. The RTS was $6.13 \pm 1.72$ in group $\mathrm{A}$ and $5.7 \pm 1.26$ in group $\mathrm{D}$ $(p=0.59)$. The ISS (AIS $>3$ ) was $40.8 \pm 8.5$ in group A and $57.5 \pm 14.1$ in group $\mathrm{D}(p=0.006)$. There were no statistically significant differences in the data between the two groups, except for the mean period between arrival and treatment, and the mean ISS. Particularly, the mean ISS was significantly higher in group D than in group A. Moreover, the multivariate analysis was further conducted for these results, and ISS showed accuracy as a prognosis predictive factor with the ROC curve (Table 6).

The overall mortality rate was $33.3 \%$. All six patients who underwent emergency surgery within $2 \mathrm{~h}$ died, four intra-operatively and two postoperatively. The causes of the intra-operative mortality were uncontrollable hemorrhage and irreversible cardiac arrest due to penetrating injury of the thoracic aorta and the intercostal arteries in three patients, and uncontrollable hemorrhage due to severe liver laceration in one.

The rate of postoperative mortality was $14.3 \%(2 / 14)$. One patient died of hemorrhagic shock due to disseminated intravascular coagulation and critical liver damage on day

Table 5 Patient outcomes

\begin{tabular}{llll}
\hline & Alive $(n=12)$ & Dead $(n=6)$ & $p$ \\
\hline Age (years [mean]/range) & $34.6 \pm 15.7(18-63)$ & $37 \pm 29.7(17-81)$ & 0.86 \\
Period between trauma and arrival & $411 \pm 1,179.5 \mathrm{~min}(28 \mathrm{~min}-3$ days $)$ & $70.5 \pm 83.6 \mathrm{~min}(9-255 \mathrm{~min})$ & 0.81 \\
Period between arrival and treatment & $47.7 \pm 130.4 \mathrm{~h}(1.8 \mathrm{~h}-20$ days $)$ & $2.6 \pm 1.8 \mathrm{~h}(0.5-5.3 \mathrm{~h})$ & 0.02 \\
ISS [mean]/(range) & $40.8 \pm 8.5(26-50)$ & $57.5 \pm 14.1(34-75)$ & 0.006 \\
RTS [mean]/(range) & $6.13 \pm 1.72(3.07-7.84)$ & $5.7 \pm 1.26(4.5-7.55)$ & 0.59 \\
\hline
\end{tabular}


Table 6 Evaluation of ISS by multivariate analysis and ROC curve

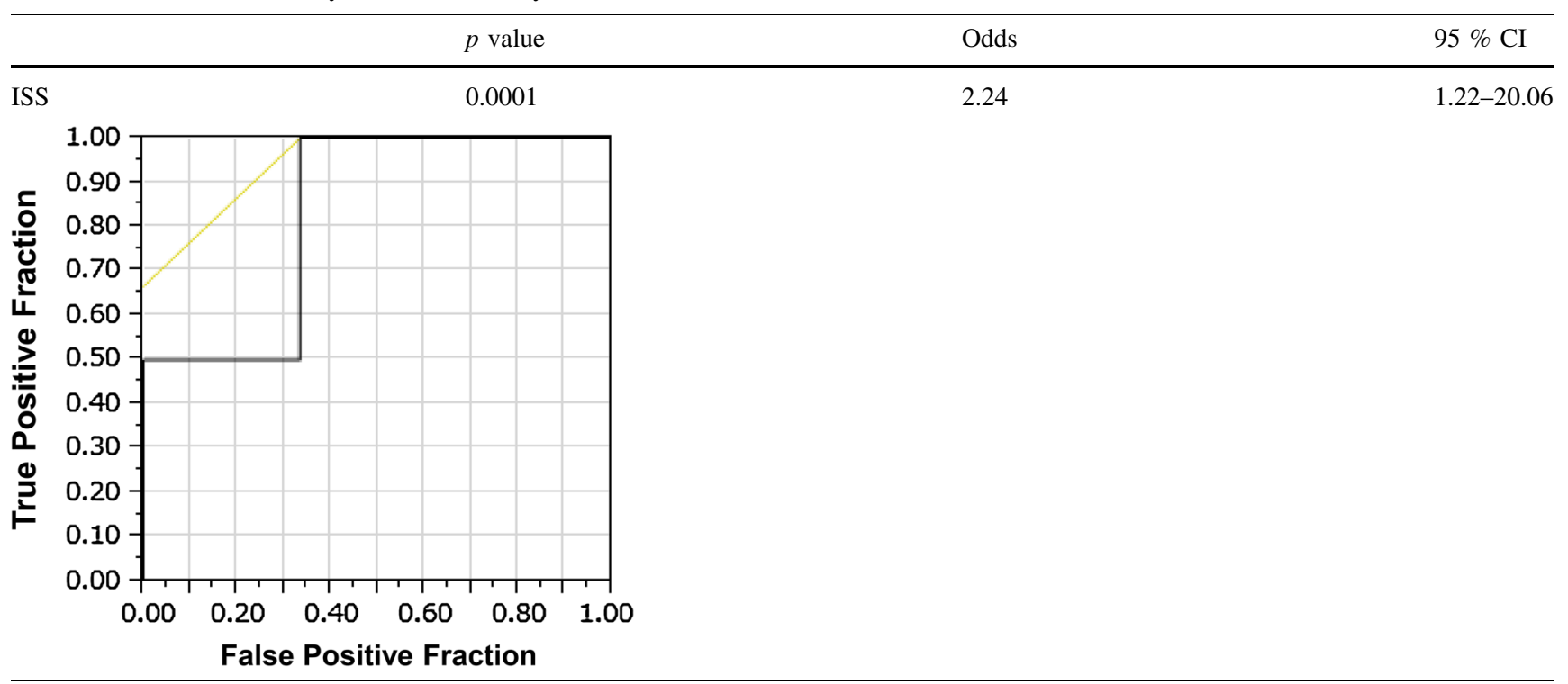

$\mathrm{AUC}=0.833$

ISS cut off point $=45.0$

CI confidence interval

2 , and the other patient died of severe pulmonary insufficiency and liver damage on the day of operation.

Eleven patients had complicated blunt torso injuries. Their causes were traffic accidents $(n=6)$ and a fall from a great height $(n=5)$.

In six patients $(42.8 \%)$, serious complications developed after surgical repair, namely acute lung injury $(n=2)$, liver insufficiency (including myonephropathic metabolic syndrome) $(n=2)$, acute renal failure $(n=1)$ and cerebral infarction $(n=1)$. Paraplegia associated with surgery did not occur in any patient.

The average hospital stay was $101.8 \pm 47.6$ days (median 81 days, range 16-263 days). Among the patients in group $\mathrm{A}$, four with brain injuries were transferred to other hospitals for rehabilitation. The remaining eight patients were doing well at the time of writing.

\section{Discussion}

We examined the preoperative demographic data, associated complications and mortality rate of patients with traumatic rupture of the thoracic aorta in acute settings. Acute rupture of the thoracic aorta due to blunt chest trauma is extremely lethal. Death occurs in up to $85 \%$ of the cases before arrival at a hospital [10-12].

Its etiology, patient status at the time of treatment and associated injuries are mainly responsible for the prognosis. Despite recent advances in surgical techniques and management, including one-lung ventilation and the use of cardiopulmonary bypass, surgical repair of the aorta is associated with high mortality. There is a general consensus concerning the necessity of surgery in cases of acute aortic rupture, but the ideal timing of repair is still controversial. In particular, the coexistence of lung contusion, intracranial, intra-abdominal or pelvic injuries and possible aggravation of extrathoracic bleeding by heparinization during aortic repair make it difficult. Therefore, delayed repair of traumatic aortic rupture is a surgical option for critically traumatic patients at risk of nonaortic associated injuries [13, 14]. In our experience, we suggest performing surgery of the aortic rupture after definite diagnosis of other actively bleeding injuries, especially in intraabdominal organs. On the other hand, we experienced that re-rupture can result in death even during a short waiting period and under controlled blood pressure. It is therefore difficult to determine the priority of treatment of multiple injuries.

Considering the results of this study, the period between arrival at a hospital and the beginning of surgery may not be directly associated with the result. More favorable results were suggested to be obtained in cases where enough time was allowed to consider various treatment options.

To date, three different surgical techniques have been used for the repair of aortic rupture: the simple clamp and sew procedure, repair with distal perfusion via left heart bypass and femoro-femoral partial cardiopulmonary 
bypass. The effects of systemic heparinization on mortality and the risk of hemorrhage in such patients with multiple injuries, particularly in those with coexisting brain or pulmonary contusions, remain unclear [15-17], because no separate analysis has been made of the different forms of distal perfusion. The standard assisted circulation technique in our institution is left heart bypass using a BioPump (Bio-Medicus) with argatroban, an antithrombin agent $[18,19]$. However, we used femoro-femoral cardiopulmonary bypass with low-dose heparin for those cases in which clamping the proximal site was difficult due to dissection or external hematoma, or for those with unstable respiration due to severe lung contusion.

We found that ISS was significantly higher in group D than in group A. As the rate of complications were higher in patients with ISS higher than 50, estimating ISS may be useful in predicting the outcome (Table 6).

Neurological complications remain a major challenge after the surgical repair of the thoracic aortic rupture. In particular, open surgery of the thoracic aorta with craniocerebral injuries comprises about 9-19\% of neurological events [20, 22]. In the current series, we experienced one patient with combined left hemiparalysis, but none with postoperative paraplegia and paraparesis. According to recent reports, the use of endovascular stentgrafts for traumatic aortic rupture reduces the risk of paraplegia and neurological events [23-25]. Endovascular stent-grafting has several benefits for polytrauma patients, such as rendering cardiopulmonary bypass unnecessary. Moreover, nonperformance of thoracotomy is associated with less bleeding, as well as shorter time for operative treatment for associated injury, which results in better clinical outcomes [24]. In 2004, Forbes et al. [25] reported that on performing laparotomy, continuous intra-abdominal bleeding was controlled by splenectomy and that they exposed the infrarenal aorta as an access route for endovascular repair of thoracic aortic injury. In this context, endovascular treatment for acute traumatic aortic rupture is feasible and can be a valid alternative to conventional open surgery in selected patients. To improve surgical mortality, we think that endovascular repair should be performed first or simultaneously with other surgical procedures if the patient is elderly or has intra-abdominal hemorrhage due to liver laceration (AIS > 3) or other vascular injuries in the torso.

However, the possible problem of endovascular treatment remains considering the risk of serious device-related complications, whether in the short, medium or long term $[24,25]$. At any rate, our institution did not adopt endovascular treatment then, and in the present study, we were unable to compare the efficacy of conventional surgical repair and endovascular treatment.

The data are small, and the study is retrospective and nonrandomized. As this study has such limitations, we could not definitively establish the superiority of any one technique over another.

\section{Conclusion}

To improve the outcome of traumatic thoracic aortic injury, the degree of multi-organ damage, the priority of treatment be evaluated accurately is important.

Patients whose ISS was higher due to uncontrollable bleeding because of intra-abdominal critical injury or blunt injuries of the thoracic aorta had poorer outcomes following conventional surgical repair by direct suturing, patch plasty or graft interposition. Therefore, we have introduce endovascular treatment and are examining the efficacy of endovascular repair for the patients whose ISS was high, or who were considered high risk for conventional repair.

Acknowledgments We are indebted to Mr. Roderick J. Turner, Assistant Professor Edward F. Barroga and Professor J. Patrick Barron, Chairman of the Department of International Medical Communications at Tokyo Medical University, for their review of the English manuscript.

Conflict of interest All the authors have declared no competing interest.

Open Access This article is distributed under the terms of the Creative Commons Attribution License which permits any use, distribution, and reproduction in any medium, provided the original author(s) and the source are credited.

\section{References}

1. Smith RS, Chang FC. Traumatic rupture of the aorta: still a lethal injury. Am J Surg. 1986;152:660-3.

2. Dosios TJ, Salemis N, Angouras D, Nonas E. Blunt and penetrating trauma of the thoracic aorta and aortic arch branches: an autopsy study. J Trauma. 2000;49:696-703.

3. Tetsuya S, Noriaki A, Masato U, et al. Japan Trauma Data Bank Report 2013 (2008-2012). Jpn Trauma Care Res. 2013;1-63.

4. Nagy K, Fabian T, Mirvis S, et al. Guidelines for the diagnosis and management of blunt aortic injury: an EAST practice management guidelines work group. J Trauma. 2000;48:1128-43.

5. Baker SP, O’Neill B, Haddon W Jr, et al. The Injury Severity Score: a method for describing patients with multiple injuries and evaluating emergency care. J Trauma. 1974;14:187-96.

6. Champion HR, Sacco WJ, Copes WS, et al. A revision of the Trauma Score. J Trauma. 1989;29:623-9.

7. Exadaktylos AK, Duwe J, Eckstein F, Stoupis C, Schoenfeld H, Zimmermann H, et al. The role of contrast-enhanced spiral CT imaging versus chest $\mathrm{X}$-rays in surgical therapeutic concepts and thoracic aortic injury: a 29-year Swiss retrospective analysis of aortic surgery. Cardiovasc J S Afr. 2005;16:162-5.

8. Chirillo F, Totis O, Cavarzerani A, Bruni A, Farnia A, Sarpellon $M$, et al. Usefulness of transthoracic and transoesophageal echocardiography in recognition and management of cardiovascular injuries after blunt chest trauma. Heart. 1996;75:301-6. 
9. Sammer M, Wang E, Blackmore CC, Burdick TR, Hollingworth W. Indeterminate CT angiography in blunt thoracic trauma: is CT angiography enough? AJR. 2007;189:603-8.

10. Lawlor K, Ott M, Forbes TL, Kribs S, Harris KA, Derose G. Endovascular management of traumatic thoracic aortic injuries. Can J Surg. 2005;48:293-7.

11. Merrill WH, Lee RB, Hammon JH, Frist WH, Stewart JR, Bender HW. Surgical treatment of acute traumatic tear of the thoracic aorta. Ann Surg. 1988;207:699-703.

12. Cardarelli MG, Mclaughlin JS, Downing SW, Brown JM, Attar A, Griffith BP. Management of traumatic rupture: a 30-year experience. Ann Surg. 2002;236:465-70.

13. Kipfer B, Leupi F, Schuepbach P, Friedli D, Althaus U. Acute traumatic rupture of the thoracic aorta: immediate or delayed surgical repair? Eur J Cardiothorac Surg. 1994;8:30-3.

14. Symbas PN, Sherman AJ, Silver JM, Symbas JD, Lackey JJ. Traumatic rupture of the aorta immediate or delayed repair? Ann Surg. 2002;235:796-802.

15. Amabile P, Collart F, Gariboldi V, Rollet G, Bartoli JM, Piquet P. Surgical versus endovascular treatment of traumatic thoracic aortic rupture. J Vasc Surg. 2004;40:873-9.

16. Miller PR, Kortesis BG, McLaughlin CA, Chen MY, Chang MC, Kon ND, et al. Complex brunt aortic injury or repair: beneficial effects of cardiopulmonary bypass use. Ann Surg. 2003;237:877-84.

17. Crestanello JA, Zehr KJ, Mullany CJ, Orszulak TA, Dearani JA, Puga FJ, et al. The effect of adjuvant perfusion techniques on the incidence of paraplegia after repair of traumatic thoracic aortic transections. Mayo Found Med Educ Res. 2006;81:625-30.
18. Kawada T, Okada Y, Hoson M, Endo S, Yokoyama M, Kitanaka $\mathrm{Y}$, et al. Argatroban, an attractive anticoagulant, for left heart bypass with centrifugal pump for repair of traumatic aortic rupture. J Thorac Cardiovasc Surg. 1999;47:104-9.

19. Kawada T, Aiba M. Traumatic rupture of the thoracic aorta. Kyobu Geka. 2004;57:630-6.

20. Lebl DR, Dicker RA, Spain DA, Brundage SI. Dramatic shift in the primary management of traumatic thoracic aortic rupture. Arch Surg. 2006;141:177-80.

21. Ferrari E, Tozzi P, von Segesser L. Thoracic aorta emergencies: is the endovascular treatment the new gold standard? Interact Cardio Vasc Thorac Surg. 2006;5:730-4.

22. Kurimoto Y, Morishita K, Kawaharada N, Fukuda J, Hachiro Y, Fujisawa Y, et al. Initial experiences in management of blunt aortic injury taking associated brain injury into consideration. Circ J. 2006;70:198-201.

23. Rousseau H, Soula P, Perreault P, Bui B, Massabuau P, Meites G, et al. Delayed treatment of traumatic rupture of the thoracic aorta with endoluminal covered stent. Circulation. 1999;99:498-504.

24. Barnard J, Humphereys J, Bittar MN. Endovascular versus open surgical repair for blunt thoracic aortic injury. Interact CardioVasc Thorac Surg. 2009;9:506-9.

25. Forbes TL, Parrry NG. Combined trauma laparotomy and endovascular repair of thoracic aortic injury. J Can Chir. 2004;47:386-7. 